\title{
Dental unit water lines: The infectious sources of Pseudomonas aeruginosa
}

\author{
A shok V. Gomashe*, Pranita A. Gulhane, Preeti G. Dharmik and A parna K . Barhanpure \\ Department of Microbiology, S.S.E.S.A's Science College, Congress Nagar, Nagpur-440012 (MS), INDIA \\ *Corresponding author. E-mail: drgomashe@ $@$ rediffmail.com \\ Received: J une 12, 2012; Revised received: J une 29, 2012; Accepted: August 25, 2012
}

\begin{abstract}
Water quality in the dental unit water lines (DUWLs) is important to the patients and dental healthcare personnel as they are at risk of being infected with Pseudomonas aeruginosa. The aim of the present study was to determine the occurrence of $P$. aeruginosa contamination in DUWLs and to study the antibiotic resistant profile. A total of 101 dental water samples including air/water spray (26), Ultrasonic scalar (24), Air rotor compressor (26) and Distilled water (25) were screened for P. aeruginosa and 67 samples were found to be contaminated by P. aeruginosa. All these isolates were further subjected to antibiotic susceptibility testing. Among these, $63(94.02 \%)$ showed resistance to ampicillin followed by $39(58.20 \%)$ to amoxicillin, $11(16.41 \%)$ to cefepime, $5(7.46 \%)$ to aztreonam and $1(1.49 \%)$ to gentamicin.
\end{abstract}

Keywords: Antibiotic resistance, Dental unit water lines, Pseudomonas aeruginosa, Water quality

\section{INTRODUCTION}

The quality of dental unit water is of considerable importance since patients and dental staff are regularly exposed to water and aerosols generated from the dental unit. Every dental unit is equipped with small bore flexible plastic tubing to bring water to different hand pieces, namely distilled water (DW), air/water spray (AWS), the ultra sonic scalar (USS) and air rotor compressor (ARC) handpiece. Although potable municipal water is normally supplied to dental units, but a few, use independent distilled or sterile water reservoirs (Barbeau et al., 1996). The contamination of Dental Unit Water lines (DUWLs) is of great concern to the dental profession, since the water in these lines has the capacity for rapid development of biofilms combined with the generation of potentially contaminated aerosols (Walker et al., 2000).

It has long known that the water collected at the output of DUWLs is densely populated with micro-organisms. A wide range of organisms have been isolated from DUWLs which include fungi, free living amoebae, protozoa, nematodes, Pseudomonas spp., K lebsiella spp. and Flavobacterium spp. (Al-Hiyasat et al., 2007). In addition there are opportunistic and true human pathogens such as P. aeruginosa derived from DUWLs has definitively been reported to give rise to infections in immunocompromised patients (Martin, 1987; Barben and Schmid, 2008).

$P$. aeruginosa is an aerobic bacterium which usually grows in wet places such as soil or any water laden habitat. Nosocomial infections caused by P. aeruginosa are frequently life threatening and difficult to control if such contaminated dental water may be ingested, inhaled in the form of aerosols or directly contaminate surgical wounds (Pankhurst et al., 1998). It is difficult to treat infections caused by P. aeruginosa due to their resistance to many commonly used disinfectants and antibiotics, like first and second generation cephalosporin (Carmeli et al., 1999). Most studies on DUWLs have been carried out but have not been fully described, in relation to multidrug-resistant $P$. aeruginosa strains. Thus, the objective of the present study was to determine the occurrence of $P$. aeruginosa contamination in DUWLs (distilled water, air/water spray, ultra sonic scalar and air rotor compressor) in dental clinics and to study the antibiotic resistant profile of isolated $P$. aeruginosa.

\section{MATERIALS AND METHODS}

Collection of samples: A total of 101 dental unit water samples from 26 dental clinics of Nagpur City, Maharashtra, were collected in a sterilized glass bottle of $15-20 \mathrm{ml}$ capacity having air tight cork by aseptic technique. The water samples were collected from distilled water (25), air/water spray (3in1 syringe) (26), ultra sonic scalar (24) and air rotor compressor (26) in sterilized glass bottle by flushing the water for 2 minutes before collection (Al-Hiyasat et al., 2007).

Transfer of water samples on culture media: The water samples were placed in an ice box and transported to the laboratory within 24 hours and kept in the refrigerator at $4^{\circ} \mathrm{C}$. On the following day, one milliliter dental water sample of each chair from different sources was inoculated in $9 \mathrm{ml}$ of MacConkey broth and incubated at $37^{\circ} \mathrm{C}$ for 24 hours. A loopful inoculum from MacConkey broth was sub-cultured on Cetrimide agar plates for isolation of P. aeruginosa. These plates were incubated 
at $37^{\circ} \mathrm{C}$ for 24 hours (Siang et al., 2012).

I solation and identification: The isolated pathogens were identified for the presence of $P$. aeruginosa on the basis of morphological, cultural and biochemical characteristics (Collee and Marr, 1996) and results were compared with Bergeys's manual of determinative bacteriology, $9^{\text {th }}$ edition.

A ntibiotic sensitivity test: All the confirmed P. aeruginosa were subsequently tested for antibiotic sensitivity patterns by disk diffusion method on Mueller Hinton agar, using six different types of antibiotic discs obtained from Hi-media Laboratories Pvt. Ltd. Mumbai (Table 1). Finally, the zone size of inhibition was recorded in $\mathrm{mm}$ (Bauer et al., 1966) and results were interpretated as per Clinical and Laboratory Standards Institute (CLSI) guidelines (CLSI, 2007).

\section{RESULTS AND DISCUSSION}

DUWLs are an integral part of dental surgery equipment, supplying water as a coolant, primarily for air turbine and ultrasonic scalar. The patient and the attending dental staff may inhale a fine spray of this water as it splashes off the surface of the patient's mouth. The presence of biofilm in DUWLs is a universal problem and pathogens from patients and the dental clinic environment can be cultivated from biofilm removed from DUWLs. The waterlines of dental units remain a potential weakness in the control of infection in the dental practice, as they can easily become contaminated with both patient-derived and municipal water impurities (Franco et al., 2005).

A total of 26 dental water chairs /clinics were included in the present study. A total of 101 dental water samples were screened for $P$. aeruginosa and 67 samples were found to be contaminated. The four different sources of dental water used were distilled water, air/water spray, ultrasonic scalar and air rotor compressor.

A total of 101 DUWLs samples including distilled water (25), air/water spray (26), ultrasonic scalar (24) and air rotor compressor (26) samples were analyzed for $P$. aeruginosa contamination. Out of these, $15(60 \%)$ distilled water, 17 (65.38\%) air/water spray, 14 (58.33\%) ultrasonic scalar and $21(80.76 \%)$ air rotor compressor samples were found to be contaminated with $P$. aeruginosa (Table 2 ). The main reason behind this contamination is that these chair systems are not operating properly; whereby nutrient-rich salivary fluids from patients leak into the water in the system providing a suitable breeding ground for bacteria (Abdulsalam et al., 2010). According to Topping et al. (1974) saliva constitutes a main source of contamination in case of the dental chair systems as the $P$. aeruginosa contamination increases dramatically with the increase of salivary fluids in the system, which contains the essential nutrients for the growth of this type of bacteria.
Table 1. Antibiotics used in the study.

\begin{tabular}{lcc}
\hline \multicolumn{2}{l}{ Antibiotics } & Concentration \\
\hline Ampicillin (A) & $10(\mathrm{mcg})$ \\
Amoxycillin (Am) & $10(\mathrm{mcg})$ \\
Aztreonam (Ao) & $30(\mathrm{mcg})$ \\
Cefepime (CPM) & $30(\mathrm{mcg})$ \\
Gentamicin (G) & $50(\mathrm{mcg})$ \\
Levofloxacin (LE) & $5(\mathrm{mcg})$ \\
\hline
\end{tabular}

The highest $P$. aeruginosa contamination was found in air rotor compressor $(80.76 \%$ ) followed by air/water spray $(65.38 \%)$. As the diameter and material of the tubing were same, the reason of this finding might be due to different water flow rates or more frequent use of air rotor compressor and air/water spray in the dental clinics (Walker et al., 2000).

The distilled water showed $60 \%$ P. aeruginosa contamination. Pankhurst (2003) reported that $P$. aeruginosa is able to thrive in low nutrient environments such as distilled water. Thus, the addition of distilled water in residual water and improper as well as less frequent cleaning of storage tank showed the possibility of contamination in distilled water. Another reason might be that if the distilled water storage tank are not disinfected on a daily basis and then stored dry, the interior of the tank becomes colonized, with both skin and water microbes. The microbes in the tank proliferate in the distilled water and contaminate the waterline (Jorgensen et al., 1999).

The bacteria that contaminate the dental chair unit waterlines can originate from two places. First, municipal water piped into the dental chair unit and, secondly, suck back of patient's saliva into the line due to lack of antiretraction valves. Even a small amount of P. aeruginosa in a municipal water system can contribute to the dental chair unit contamination problem because dental chair units provide a different environment with small bores, narrow lumens and periods of stagnant water. However, if the water is well maintained according to current hygiene guidelines, the prevalence of $P$. aeruginosa in the public water supply is extremely low (Barben et al., 2005). As P. aeruginosa can be recovered from the oral cavity of < “ $4 \%$ of healthy individuals (Botzenhart et al., 1987), it is therefore possible that some of these bacteria are aspirated into the DUWLs through a defective check valve and are able to colonize in the waterlines. As the suction system hoses and pipe work are frequently wet, they provide an environment that is conducive to the growth and proliferation of biofilms which adhere to the inner surfaces of the lines. This biofilm protects the bacteria both from being washed away by the water flow and from many types of antimicrobial water treatment (Donlan, 2002). 
Table 2. Isolation of P. aeruginosa from different sources of DUWLs.

\begin{tabular}{lcc}
\hline Different sources of DUWLs & $\begin{array}{c}\text { Total } \\
\text { no. of samples }\end{array}$ & $\begin{array}{c}\text { P. aeruginosa } \\
\text { analyzed }\end{array}$ \\
\hline Distilled Water & 25 & $15(60 \%)$ \\
Air/ Water Spray & 26 & $17(65.38 \%)$ \\
Ultra Sonic Scalar & 24 & $14(58.33 \%)$ \\
Air Rotor Compressor & 26 & $21(80.76 \%)$ \\
\hline
\end{tabular}

A total of six different types of antibiotics namely ampicillin (A), amoxicillin (Am), aztreonam (A), cefepime (CPM), gentamicin $(\mathrm{G})$, levofloxacin (LE) were used against isolated $P$. aer uginosa (Table 1). Thus, a total number of 402 antibiotic discs were tested against P. aeruginosa. Out of these, P. aeruginosa showed sensitivity towards 283 antibiotics while showed resistance to 119 antibiotic discs (Table 3).

Out of 67 P. aeruginosa, 63 (94.02\%) showed resistance to ampicillin followed by $39(58.20 \%)$ to amoxicillin, 5 (7.46\%) to aztreonam, $11(16.41 \%)$ to cefepime, $1(1.49 \%)$ to gentamicin. The maximum no. of P. aeruginosa showed resistance to ampicillin, while only one $P$. aeruginosa showed resistance to gentamicin. It means that 66 $(98.50 \%)$ of $\mathrm{P}$. aer uginosa were sensitive to gentamicin. However, all 67 (100\%) P. aeruginosa were sensitive to levofloxacin (Table 3). Being Gram negative bacteria, most $P$. aeruginosa are naturally resistant to penicillin and the majority of related beta-lactam antibiotics.

Thus, ampicillin should be avoided to use against $P$. aeruginosa while levofloxacin, gentamicin, aztreonam and cefepime should be used against infections in dental clinics. The clinical importance of the presence of $P$. aeruginosa is not known, despite the fact that it causes significant morbidity and mortality in immunocompromised subjects showing burns, cystic fibrosis, chronic bronchitis and cancer (Barbeau et al., 1998).

Since the origins of dental unit water contamination are now more clearly defined, substantial progress can be made by dental manufacturers and the scientific community in approaches to prevention and control of contamination. Due to the multiple ports of entry to the DUWLs system for microbes, no single method or device can completely eliminate the potential for cross infection.

Based on the result and within the limitations of this study, it was concluded that DUWLs are not totally free from $P$. aeruginosa contamination. Contamination of DUWLs is universal. It is difficult to eradicate the biofilm in these tubing and prevent its regrowth. Nevertheless, every attempt has to be taken to minimize the contamination of the tubing in order to maximize the health of the dental health care personnel and the patient. Although the number of published cases of infection resulting from exposure to water from contaminated DUWLs is limited, there is a medico-legal requirement to comply with potable water standards and to confirm to public perceptions on water safety.

Dentists are encouraged to follow manufacturers' instruction in maintaining the DUWLs and use disinfectant whenever possible. Until ideal guidelines for maintaining DUWLs is released by a professional body, flushing water for 20-30 seconds before starting the morning session and in between patient treatments, remains the most economic way of reducing bacterial load in DUWLs.

Chairside devices for monitoring microbial quality of the DUWLs need to be developed and are an essential component to assure satisfactory water quality. Future research into the prevention of biofilm proliferation is being actively promoted by the American dental

Table 3. Antibiotic resistance profile of P. aeruginosa isolated from DUWLs.

\begin{tabular}{lcccccccccc}
\hline Antibiotics & $\begin{array}{c}\text { Distilled } \\
\text { water }(\mathrm{n}=15)\end{array}$ & $\begin{array}{c}\text { Air/W ater } \\
\text { spray }(\mathrm{n}=17)\end{array}$ & $\begin{array}{c}\text { Ultra sonic } \\
\text { scalar }(\mathrm{n}=21)\end{array}$ & \multicolumn{2}{c}{$\begin{array}{c}\text { Air rotor } \\
\text { compressor } \\
(\mathrm{n}=21)\end{array}$} & $\begin{array}{c}\text { Total } \\
\text { resistance } \\
(\mathrm{n}=67)\end{array}$ \\
\hline \multirow{2}{*}{ Ampicillin } & $\mathrm{R}$ & $\mathrm{S}$ & $\mathrm{R}$ & $\mathrm{S}$ & $\mathrm{R}$ & $\mathrm{S}$ & $\mathrm{R}$ & $\mathrm{S}$ & $\mathrm{R}$ & $\mathrm{S}$ \\
\cline { 2 - 11 } Amoxycillin & 13 & 02 & 17 & 0 & 13 & 01 & 20 & 01 & 63 & 04 \\
Aztreonam & 08 & 07 & 10 & 07 & 08 & 06 & 13 & 08 & 39 & 28 \\
Cefepime & 01 & 14 & 02 & 15 & 0 & 14 & 02 & 19 & 05 & 62 \\
Gentamicin & 04 & 11 & 04 & 13 & 0 & 14 & 03 & 18 & 11 & 56 \\
Levofloxacin & 01 & 14 & 0 & 17 & 0 & 14 & 0 & 21 & 01 & 66 \\
Total resistance & 0 & 15 & 0 & 17 & 0 & 14 & 0 & 21 & 0 & 67 \\
\hline
\end{tabular}


association and other dental organizations and government agencies around the world.

Increase in washing frequency of water container and the flushing through of waterlines between patient and at the beginning and end of the working day eliminates the bacterial contamination, which is a useful method to eliminate oral flora entering the waterline via suck back. Anti-retraction valves should be fitted on all handpieces and must be regularly monitored and maintained. Where water is used as a hand piece irrigant in surgical procedures, sterile water or saline water should be provided from a separate and preferably single use source which cannot be contaminated by passage through the dental unit waterlines. Flushing and autoclaving the handpieces will also aid removal of other contaminants from the oral cavity. Routine maintenance of handpieces should include checking the function of the antiretraction valve.

\section{ACKNOW LEDGEMENT}

The authors wish to acknowledge the dental director, officers and staffs of dental clinics in Nagpur for their valuable assistance in carrying out this project.

\section{REFERENCES}

Abdulsalam, I., Rafida, A., Ehae. Abo-Jnha, B. and Kald Tainah, C. (2010). Assessment of microbial pollution of the dental chairs water system (Pseudomonas aer uginosa) in the City of Tripoli, Libya. World Academy of Science, Engineering and Technology, 66: 60-63.

Al-Hiyasat, A.S., Ma'ayeh, S.Y., Hindiyeh, M.Y. and Khander, Y.S. (2007). The presence of Pseudomonas aeruginosa in the dental unit waterline systems of teaching clinics. Int J Dent Hyg, 5: 36-44.

Barbeau, J., Tanguay, R., Faucher, E., Avezard, C., Trudel, L., Cote, L. and Prevost, A.P. (1996). Multiparametric analysis of waterlines contamination in dental units. Appl Environ Microbiol, 62: 3954-3959.

Barbeau, J., Gauthier, C. and Payment, P. (1998). Biofilms, infectious agents and dental unit waterlines: a review. $C$ an J Microbiol, 44: 1019-1028.

Barben, J., Hafen, G. and Schmid, J. (2005). Swiss paediatric respiratory research group Pseudomonas aeruginosa in public swimming pools and bathroom water of patients with cystic fibrosis. J Cyst Fibros, 4: 227-231.

Barben, J. and Schmid, J. (2008). Dental units as infection sources of P seudomonas aeruginosa. European Respiratory J ournal, 32(4): 1122-1123.
Bauer, A.W., Kirby, W.M.M., Sherris, J.C. and Turck, M. (1966). Antibiotic susceptibility testing by a standardized single disc method. Am J C lin Pathol, 45: 493-496.

Botzenhardt, K., Puhr, O.F. and Doring, G. (1987). Pseudomonas aeruginosa in the oral cavity of healthy adults: frequency and age distribution. Zentralbl Bakteriol M ikrobiol Hyg Abt Orig B, 180: 471-479.

Carmeli, Y., Troillet, N. and Etiopoulos, G.M. (1999). Emergence of antibiotic-resistant Pseudomonas aer uginosa: comparison of risk associated with different antipseudomonal agents. Antmicrob Agents Chemother, 43: 1379-1382.

CLSI (2007). Performance standards for antimicrobial susceptibility testing: $17^{\text {th }}$ Informational supplement. Approved standard M100-S17, Wayne, USA: Clinical and Laboratory Standards Institute.

Collee, J.G. and Marr, W. (1996). Tests for identification of bacteria and Laboratory control of antimicrobial therapy. Chapter 7 and 8. In: Mackie \& McCartney Practical Medical Microbiology, Collee, J.G., Fraser, A.G., Marmion B.P. and Simmons, A. (Ed.), 14th ed. (pp 131-151), Churchill Livingstone: New York.

Donlan, R.M. (2002). Biofilms: Microbial life on surfaces. Emerg Infect Dis, 8: 881-890.

Franco, F.F.S., Spratt, D., Leao, J.C. and Porter, S.R. (2005). Biofilm formation and control in dental unit waterlines. Biofilms, 2(1): 9-17.

Jorgensen, M.G., Detsch, S.G. and Wolinsky, LE. (1999). Disinfection and monitoring of dental unit waterlines. Gen Dent, 53:152-156.

Martin, M.V. (1987). The significance of the bacterial contamination of dental unit water systems. Br Dent J, 163:152-153.

Pankhurst, C.L., Johnson, N.W. and Woods, R.G. (1998). Microbial contamination of dental unit waterlines: the scientific argument. International D ental J ournal, 48(4): 359368.

Pankhurst, C.L. (2003). Risk assessment of dental unit waterline contamination. Primary D ental C are, 10(1): 5-10.

Siang, M.M., Yunus, Z., Yunus, A.R.M., Ahmad, Z. and Toosa, H. (2012). The microbiological quality of water from dental unit waterlines in Malaysian Armed Forces dental centres Archives of O r ofacial Sciences, 7(1): 1-7.

Topping, J.W., Popkes, D.L. and Disanto, D.A. (1974). Salivary Pseudomonas aeruginosa. Oral Surgery Oral Medicine Oral Pathology, 38(1): 42-46.

Walker, J.T., Bradshaw, D.J., Bennett, A.M., Fulford, M.R. Martin, M.V. and Marsh, P.D. (2000). Microbial biofilm formation and contamination of dental-unit water systems in general practice. Appl E nviron M icrobiol, 66: 3363-3367. 